\title{
Impact of successful transsphenoidal surgery on cardiovascular risk factors in acromegaly
}

\author{
Marie-Lise Jaffrain-Rea ${ }^{1,2}$, Giuseppe Minniti ${ }^{3}$, Carlo Moroni ${ }^{4}$, Vincenzo Esposito ${ }^{3}$, Elisabetta Ferretti ${ }^{1}$, \\ Antonio Santoro ${ }^{5}$, Tommaso Infusino ${ }^{4}$, Guido Tamburrano ${ }^{6}$, Giampaolo Cantore ${ }^{5}$ and Rosario Cassone ${ }^{4}$ \\ ${ }^{1}$ Department of Experimental Medicine, University of L'Aquila, L'Aquila, Italy, ${ }^{2}$ Fondazione Carlo Ferri, Monterotondo, Italy, ${ }^{3}$ Division of Neurosurgery, \\ IRCCS Neuromed, Pozzilli, Italy and Departments of ${ }^{4}$ Internal Medicine, ${ }^{5}$ Neurological Sciences and ${ }^{6}$ Clinical Sciences, University of Rome 'La Sapienza', \\ Policlinico Umberto $1^{\circ}$, Rome, Italy
}

(Correspondence should be addressed to Marie-Lise Jaffrain-Rea, Dipartimento di Medicina Sperimentale Università degli Studi dell'Aquila, Via Vetoio, Coppito 2, 67100 L'Aquila (AQ), Italy; Email: jaffrain.ml.rea@katamail.com)

\begin{abstract}
Background: Cardiac abnormalities develop in patients with acromegaly as a consequence of effects of GH/IGF-I on the heart and related cardiovascular risk factors.

Objective: To evaluate the possible contribution of postoperative variations in blood pressure (BP), glucose tolerance and insulin sensitivity to the cardiac improvement reported in patients who have been cured of acromegaly.

Design: Thirty-one patients with acromegaly were studied before and 6 months after successful transsphenoidal surgery, defined by normal age-related IGF-I concentrations and glucose-suppressed GH concentrations $<1 \mu \mathrm{g} / \mathrm{l}$.

Methods: Cardiovascular parameters were assessed by Doppler echocardiography and 24-h ambulatory blood pressure monitoring. Insulin sensitivity indexes were calculated on the basis of fasting and post-load glycaemia and insulinaemia and referred to as $\mathrm{HOMA}_{\mathrm{ISI}}$ and $\mathrm{OGTT}_{\mathrm{ISI}}$, respectively. Results: Successful surgery was confirmed to improve left ventricular mass index (LVMI) and diastolic filling significantly. Mean 24-h systolic BP values decreased $(P=0.009)$ and BP rhythm was restored in 12 of 15 patients with a blunted preoperative profile. Glucose tolerance normalized in patients with preoperative glucose intolerance $(n=7)$ or diabetes mellitus $(n=3)$. HOMA $\mathrm{ISI}_{\text {and }}$ OGTT $\mathrm{HSI}_{\text {Increased }}$ $(P=0.0001$ for each parameter), indicating a marked improvement in insulin sensitivity. The postoperative reduction in LVMI correlated with increased insulin sensitivity $(P<0.001$ for both indexes), but not with other parameters. Improved diastolic filling correlated with the reduction in LVMI.

Conclusions: Successful surgery in patients with acromegaly induces a significant improvement in haemodynamic and metabolic risk factors. This study suggests a direct link between insulin resistance and acromegalic cardiomyopathy.
\end{abstract}

European Journal of Endocrinology 148 193-201

\section{Introduction}

Acromegaly is associated with an increased morbidity and mortality, especially from cardiovascular complications $(1-5)$. Cardiac abnormalities have been extensively described in patients with acromegaly (6) and mainly consist of precociously increased cardiac mass and abnormalities of diastolic function, which can be easily detected by Doppler echocardiography (7-9). Systolic function at rest is preserved until a late stage of the disease, subclinical abnormalities of cardiac performance being best detected at exercise (6).

From a physiopathological point of view, it is well accepted that growth hormone/insulin-like growth factor-I (GH/IGF-I) hypersecretion in itself contributes to the existence of a specific cardiomyopathy $(6,9)$, the myocardial effects of chronic $\mathrm{GH}$ excess and the direct growth-promoting role of IGF-I being supported by in vivo (10) and in vitro experimental models (11) respectively. Other factors, however, could contribute to the increased cardiovascular risk reported in patients with acromegaly. The incidence of hypertension, a wellknown risk factor for cardiovascular events in the general population, is increased in these patients $(1,4,12)$, and the frequently reported abnormalities in their blood pressure (BP) circadian rhythm may represent a significant additional risk factor $(13-16)$. Moreover, acromegaly is associated with frequent abnormalities of glucose metabolism, including impairment of glucose tolerance and reduced insulin sensitivity $(1,15,17)$, 
which represent well-recognized cardiovascular risk factors in the general population. Close interrelations between abnormalities of glucose tolerance, blood pressure (BP) values and cardiac abnormalities have also been documented recently in patients with acromegaly $(15,18)$.

Normalization of GH/IGF-I secretion is able to improve significantly both cardiac mass and function in patients with acromegaly, as reported after either medical treatment with somatostatin analogues (19, 20) or surgical treatment by transsphenoidal surgery (TSS) $(21-23)$. It is not clear, however, to what extent GH/IGF-I reduction in itself is responsible for cardiac improvement and whether it is able to reduce the overall cardiovascular risk significantly in these patients. Using 24-h ambulatory blood pressure monitoring (ABPM), which provides accurate information about BP values and in particular the BP profile $(24$, $25)$, we have recently reported a significant decrease in systolic BP 6 months after successful TSS (22), which could be observed even in elderly patients with acromegaly (23). At the same time, it was possible to restore the circadian $\mathrm{BP}$ rhythm in most patients who showed a blunted preoperative rhythm (22). Of note, glucose tolerance also normalized in patients with preoperative glucose intolerance or diabetes mellitus (23). Similarly, a marked postoperative improvement in insulin sensitivity, accompanied by a complete reversal of related glucose and lipid metabolism abnormalities, had been demonstrated previously in a small series of patients with acromegaly, by means of methodology based on a euglycaemic clamp $(26,27)$. The difficulty of assessing insulin sensitivity with such sophisticated techniques, which hampers the study of large series, can be overcome by the use of variable indexes of insulin sensitivity (ISI), which can be simply deduced from measurements of plasma glycaemia and insulinaemia, obtained either in fasting conditions according to the homeostatic model assessment (HOMA) (28) or during an oral glucose tolerance test (OGTT) (29) the latter index correlating best with data obtained by euglycaemic clamp (29). These parameters are also applicable to patients with acromegaly, and a recent study based on the use of the HOMA index has suggested that insulin resistance is reduced in these patients, regardless of their glucose tolerance status, patients who fail to counterbalance insulin resistance with an increased $\beta$-cell function developing glucose intolerance or diabetes (30).

The aim of the present study was therefore to evaluate the effect of successful TSS on BP, glucose tolerance and insulin sensitivity in a prospective series of patients with acromegaly, in order to provide new insights into the mechanisms leading to postoperative cardiac improvement in patients cured of their acromegaly, and to evaluate the possible impact of postoperative normalization of GH/IGF-I on the overall cardiovascular risk in these patients.

\section{Patients and methods}

\section{Patients}

Thirty-one patients with acromegaly who underwent successful TSS (16 men and 15 women, mean age $48.1 \pm 11.2$ years) were included in this prospective study. Data from $50 \%$ of this group had been included in a recent report (20). Acromegaly was diagnosed on the basis of typical clinical features, increased fasting plasma GH concentrations, not suppressible below $2 \mu \mathrm{g} / \mathrm{l}$ during an OGTT performed with $75 \mathrm{~g}$ glucose, and plasma IGF-I, adjusted for age, above the highnormal limit. At the time of surgery, pituitary microor macroadenomas were demonstrated by magnetic resonance imaging (MRI) in six and 25 patients, respectively, including 10 with suprasellar extension; no patient had visual defects or a pituitary hormone deficit. No patient received preoperative medical treatment for acromegaly. All patients underwent TSS, and biochemical cure was defined strictly, at 6 months, by glucose-suppressed plasma $\mathrm{GH}$ concentrations less than $1 \mu \mathrm{g} / \mathrm{l}$ and normal age-corrected IGF-I values, as recommended by the most recent consensus conference (31). Patients who failed to meet strict criteria for surgical cure, or who suffered from secondary cardiopathy, such as ischaemic or valvular disease or cardiac failure, were excluded from the study.

\section{Hormone assays}

Plasma GH concentrations were determined by IRMA (Biodata Diagnostic, Rome, Italy) with a limit of detection of $0.1 \mu \mathrm{g} / \mathrm{l}$, and plasma IGF-I concentration by RIA after acid-ethanol extraction (Diagnostic System Laboratories, Webster, Texas, USA). The following age-corrected IGF-I plasma concentrations were considered normal: $20-30$ years, $<456 \mu \mathrm{g} / \mathrm{l} ; 31-40$ years, $<370 \mu \mathrm{g} / \mathrm{l} ; 41-50$ years, $<306 \mu \mathrm{g} / \mathrm{l}$; $>50$ years, $<257 \mu \mathrm{g} / \mathrm{l}$. Plama insulin was measured in fasting conditions and during OGTT by RIA (Biochem Immunosystems Italia S.p.A., Milan, Italy).

\section{Echocardiographic studies}

Left ventricular mass (LVM) and LVM index (LVMI) were determined by echocardiography as previously reported (9), left ventricular hypertrophy (LVH) being defined as LVMI exceeding $134 \mathrm{~g} / \mathrm{m}^{2}$ in men and $110 \mathrm{~g} / \mathrm{m}^{2}$ in women (32). Left ventricular diastolic function was evaluated by the following Doppler echocardiographic parameters: isovolumetric relaxation time (IRT; an index of left ventricular relaxation properties), and the ratio of early (E) and late (A) transmitral peak flow velocity (E/A; an index of left ventricular filling), as described previously (9). Echocardiography was performed by a single observer (C M). 


\section{Blood pressure}

Blood pressure was measured by standard mercury sphygmomanometer, taking three consecutive casual measurements, in our outpatient clinics. Patients with systolic BP (SBP) $>140 \mathrm{mmHg}$ or diastolic BP (DBP) $>90 \mathrm{mmHg}$, or both, were considered hypertensive (33). In addition, all patients were studied by non-invasive ABPM with recordings every $15 \mathrm{~min}$ from $0600 \mathrm{~h}$ to $2300 \mathrm{~h}$ and every $30 \mathrm{~min}$ for the remainder of the time, using an A\&D TM2420 monitor (7th model, A\&D Co., Tokyo, Japan). Heart rate and mean diurnal, nocturnal and 24-h BP values were obtained. The diurnal period was considered to be from $1000 \mathrm{~h}$ to $2200 \mathrm{~h}$, and the nocturnal period from $0000 \mathrm{~h}$ to $0600 \mathrm{~h}$, in order to exclude transition periods in which BP often undergoes sudden and marked variations (34). Hypertension was defined as mean $\mathrm{BP} \geq 135 / 85 \mathrm{mmHg}$ for diurnal $\mathrm{BP}$ values and $\geq 120 / 75 \mathrm{mmHg}$ for nocturnal $\mathrm{BP}$ values (33). A reduction of nocturnal mean BP values that was more than $10 \%$ of the corresponding diurnal values was considered to represent a normal 24-h BP profile (33).

\section{Glucose tolerance and insulin sensitivity}

Glucose tolerance was defined according to the American Diabetes Association guidelines as normal glucose tolerance (NGT), impaired glucose tolerance (IGT), or diabetes mellitus (35). The indexes of insulin sensitivity were derived from plasma fasting and post-load glucose and insulin concentrations according the following formulae:

$$
\begin{aligned}
\text { HOMA }_{\text {ISI }}= & 405 / \text { fasting insulin }(\mu \mathrm{U} / \mathrm{ml}) \\
& \times \text { fasting glucose }(\mathrm{mg} / \mathrm{dl}), \\
& \text { according to the HOMA model }(28) \\
\text { OGTT }_{\text {ISI }}= & (10000 / \text { square root of [fasting glucose } \\
& \times \text { fasting insulin] } \times[\text { mean glucose } \\
& \times \text { mean insulin during OGTT] } \\
& \text { as previously described }(29)
\end{aligned}
$$

Two age- and sex- matched groups with different body mass index (BMI; normal value $<25 \mathrm{~kg} / \mathrm{m}^{2}$, mean $22.4 \pm 1.3 \mathrm{~kg} / \mathrm{m}^{2} ;$ high values $\geq 25 \mathrm{~kg} / \mathrm{m}^{2}$, mean $27.1 \pm 1.6 \mathrm{~kg} / \mathrm{m}^{2}$ ) were used as controls.

\section{Postoperative follow-up}

Clinical evaluation, OGTT with glucose, GH and insulin determination, 24-h ABPM and Doppler echocardiographic studies were obtained in all patients before and 6 months after TSS.

\section{Statistical analysis}

Data are presented as mean \pm standard deviation (S.D.). The non-parametric Wilcoxon test was used to compare both pre- and postoperative data obtained in patients with acromegaly and metabolic data obtained in the patients and in control individuals. Correlations between quantitative variables were studied by simple and multiple regression as appropriate. The Statview 5.0 software for PC was used for statistical analysis. $P<0.05$ was considered significant.

\section{Results}

\section{General results}

The main bioclinical characteristics of the patients before surgery are shown in Table 1. After surgery, age-corrected IGF-I concentrations were normalized $(218.0 \pm 83.4 \mu \mathrm{g} / \mathrm{l}$ compared with $655.4 \pm 140.5 \mu \mathrm{g} / \mathrm{l}$, $P=0.001)$, and GH concentrations were normally suppressed during OGTT, to less than $1 \mu \mathrm{g} / \mathrm{l}$ in all patients, by definition. MRI showed complete removal of tumour in all patients, and two patients required replacement treatment with gonadal steroids and levothyroxine for partial acquired hypopituitarism.

\section{Cardiovascular parameters}

Pre- and postoperative cardiovascular parameters are summarized in Table 2.

Before surgery Fourteen of 31 patients met criteria for $\mathrm{LVH}(45.2 \%)$. The mean diurnal DBP values were significantly lower than the corresponding clinical values $(P<$ $0.005)$ and, although diurnal BP values were significantly greater than the corresponding nocturnal values $(P<0.005$ for both SBP and DBP $)$, the normal circadian BP rhythm was lost in 15 patients. Eleven of the 14 patients considered hypertensive by clinical measurement were also found to be hypertensive by $\operatorname{ABPM}(35.5 \%)$.

After surgery A significant postoperative decrease in LVM and LVMI was observed by echocardiography

Table 1 Preoperative clinical and hormonal characteristics of 31 successfully operated patients with acromegaly

\begin{tabular}{lc}
\hline Sex $(\mathrm{M} / \mathrm{F})$ & $16 / 15$ \\
Age $($ years) & $48.1 \pm 11.2$ \\
$\mathrm{BMI}\left(\mathrm{kg} / \mathrm{m}^{2}\right)$ & $27.1 \pm 1.8$ \\
Normal $\left(<25 \mathrm{~kg} / \mathrm{m}^{2}\right)(n=7)$ & $23.7 \pm 1.1$ \\
High $\left(\geq 25 \mathrm{~kg} / \mathrm{m}^{2}\right)(n=24)$ & $27.9 \pm 1.6$ \\
Disease duration (years) & $8.3 \pm 2.5$ \\
Hypertension $(n)$ & 11 \\
Abnormalities of glucose tolerance $(n)$ & 10 \\
Impaired $(\mathrm{IGT})$ & 7 \\
Diabetes mellitus & 3 \\
Plasma GH $(\mu \mathrm{g} / \mathrm{l})$ & $30.9 \pm 21.1$ \\
Plasma IGF-I $(\mu \mathrm{g} / \mathrm{l})$ & $665.4 \pm 270.5$
\end{tabular}


Table 2 Pre- and postoperative cardiovascular parameters in 31 successfully operated patients with acromegaly

\begin{tabular}{lccc}
\hline & $\begin{array}{c}\text { Before } \\
\text { surgery }\end{array}$ & $\begin{array}{c}\text { After } \\
\text { surgery }\end{array}$ & $\boldsymbol{P}$ \\
\hline Clinical BP & & & \\
SBP (mmHg) & $133.9 \pm 12.6$ & $128.0 \pm 14.2$ & 0.007 \\
DBP (mmHg) & $86.3 \pm 7.6$ & $83.0 \pm 7.4$ & 0.01 \\
ABPM & & & \\
24-h heart rate (beats/min) & $80.1 \pm 11.2$ & $73.1 \pm 12.2$ & 0.01 \\
24-h SBP (mmHg) & $129.2 \pm 16.2$ & $122.8 \pm 11.3$ & 0.009 \\
24-h DBP (mmHg) & $72.7 \pm 7.5$ & $72.9 \pm 2.8$ & $\mathrm{~ns}$ \\
Daytime SBP (mmHg) & $136.5 \pm 16.7$ & $129.4 \pm 14.5$ & 0.005 \\
Daytime DBP (mmHg) & $78.6 \pm 7.6$ & $77.0 \pm 8.7$ & $\mathrm{~ns}$ \\
Night-time SBP (mmHg) & $115.3 \pm 13.4$ & $111.1 \pm 10.9$ & 0.01 \\
Night-time DBP (mmHg) & $65.9 \pm 8.1$ & $65.8 \pm 9.0$ & $\mathrm{~ns}$ \\
Blunted BP profile ( $n$ ) & 15 & 3 & - \\
Doppler echocardiography & & & \\
LVM (g) & $222.9 \pm 49.9$ & $182.3 \pm 46.2$ & $<0.0001$ \\
LVMI (g/m ${ }^{2}$ ) & $121.6 \pm 25.2$ & $97.3 \pm 22.4$ & 0.0003 \\
IRT (ms) & $122.1 \pm 22.5$ & $104.8 \pm 10.4$ & 0.0004 \\
E/A & $0.94 \pm 0.18$ & $1.10 \pm 0.14$ & 0.008 \\
\hline
\end{tabular}

( $P<0.0001$ and $P<0.0005$, respectively), and 12 of 14 patients who previously met criteria for LVH had postoperative LVMI values within the normal range. Left ventricular function improved significantly, as indicated by a significant decrease in IRT $(P=0.0004)$ and an increase in the E/A ratio $(P=0.0008)$. Significant decreases in clinical SBP and DBP were observed after surgery $(P=0.007$ and $P=0.01)$. Significant postoperative decreases in 24 -h, diurnal and nocturnal
SBP values $(P=0.009, P=0.005$ and $P=0.01$ respectively), but not in the corresponding $\mathrm{DBP}$, were also observed by ABPM, and four of 11 patients who were previously considered to be hypertensive had normal diurnal BP values. In addition, a circadian rhythm of $\mathrm{BP}$ was restored in 12 of 15 patients with a blunted preoperative BP profile.

\section{Glucose tolerance and insulin sensitivity}

Data obtained from pre- and postoperative OGTT in patients with acromegaly are shown in Fig. 1. The corresponding $\mathrm{HOMA}_{\mathrm{ISI}}$ and $\mathrm{OGTT}_{\mathrm{ISI}}$ compared with those in control groups are presented in Fig. 2.

Before surgery NGT was observed in 21 patients, whereas $10(32.2 \%)$ showed abnormalities of glucose tolerance consisting of either IGT $(n=7)$ or diabetes mellitus $(n=3)$. A significant reduction in insulin sensitivity was observed in patients with acromegaly compared with controls: HOMA ISI $_{\text {in }}$ the patients (0.24 \pm 0.11$)$ was significantly lower than that in controls with either normal or high BMI $(0.61 \pm 0.16$, $P=0.0001$ and $0.42 \pm 0.12, P=0.0005$ respectively); OGTT $_{\text {ISI }}$ in patients with acromegaly $(2.4 \pm 1.3)$ was significantly lower than that in controls with either normal or high BMI $(6.3 \pm 1.7, P=0.0001$ and $4.3 \pm$ $1.1, P=0.0007$ respectively). Both indexes were also significantly lower in controls with normal BMI than in those with high BMI $\left(P=0.0006\right.$ for HOMA ${ }_{\text {ISI }}$ and $(a)$

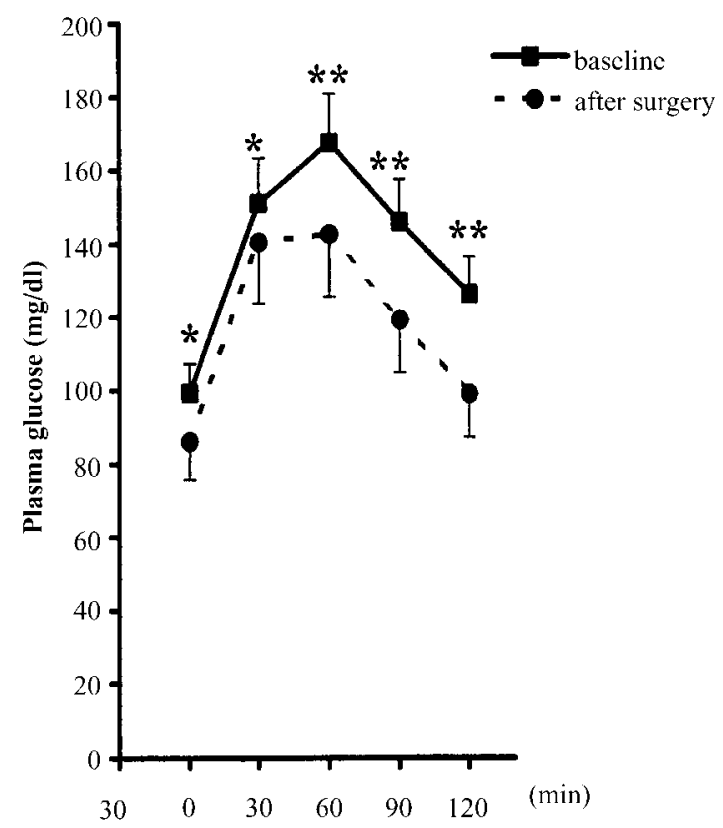

(b)

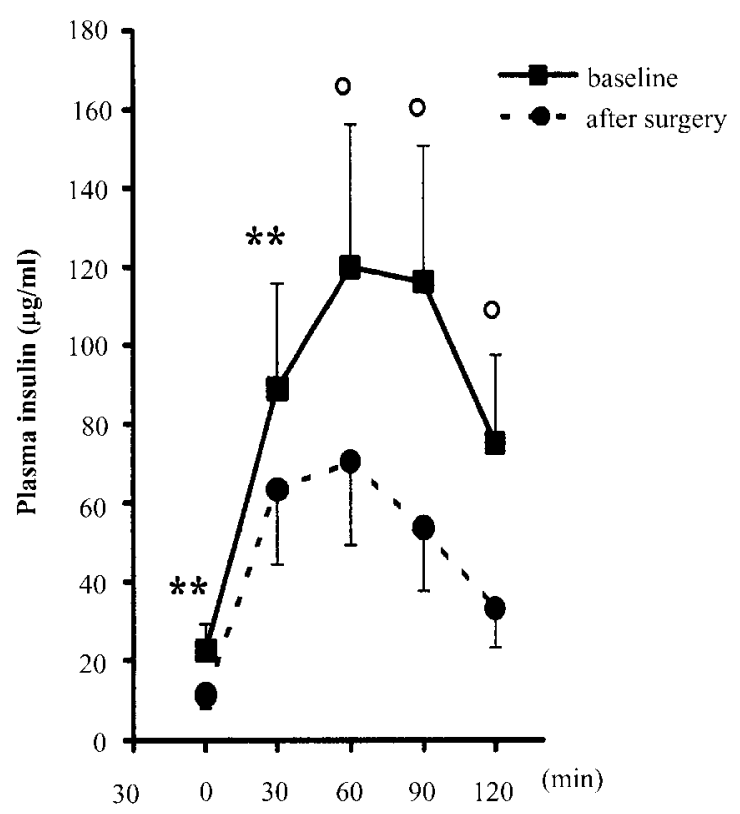

Figure 1 Effects of successful TSS on plasma glucose and insulin concentrations in patients with acromegaly. (a) Plasma glucose and (b) insulin concentrations during OGTT were plotted in 31 patients who were eventually successfully cured of their acromegaly, before and 6 months after surgery. Values are expressed as means \pm S.D. ${ }^{\star} P<0.01 ;{ }^{\star \star} P<0.005 ;{ }^{\circ} P<0.001$. 

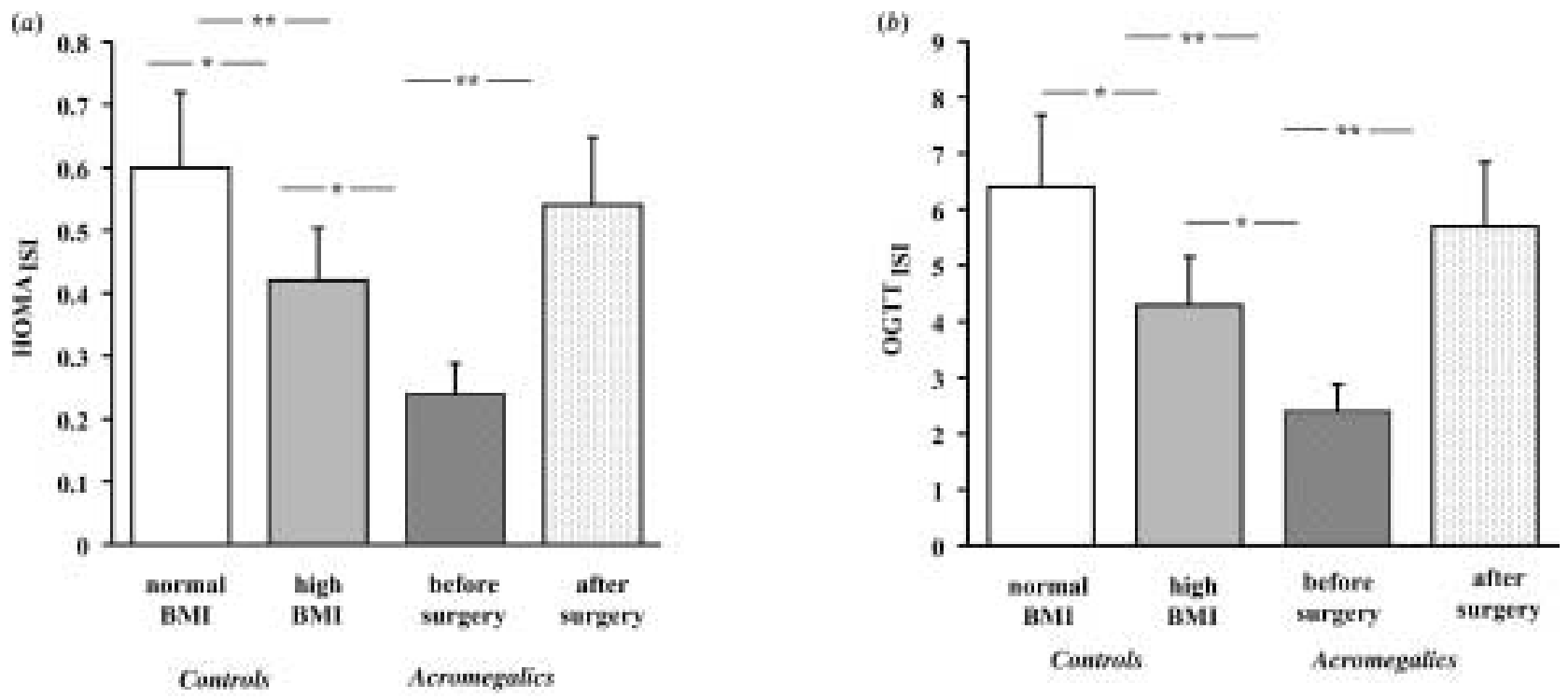

Figure 2 Insulin sensitivity in patients with acromegaly and in control individuals. Mean insulin sensitivity indexes (ISI) obtained from (a) fasting plasma glucose and insulin concentrations $\left(\mathrm{HOMA}_{I S I}\right)$, and $(b)$ plasma glucose and insulin during OGTT (OGTT $\mathrm{OSI}_{\text {ISI }}$ were plotted in 31 patients with acromegaly before and 6 months after successful TSS, and compared with two sex- and age-matched control groups with different BMI. Values are expressed as means \pm S.D. ${ }^{\star} P<0.001 ;{ }^{\star \star} P<0.0005$.

$P=0.0005$ for $\left.\mathrm{OGTT}_{\mathrm{ISI}}\right)$. In contrast, no significant difference in either $\mathrm{HOMA}_{\mathrm{ISI}}$ or $\mathrm{OGTT}_{\mathrm{ISI}}$ could be observed between patients with acromegaly with normal or high BMI (data not shown).

After surgery NGT was observed in all patients. A significant postoperative improvement in insulin sensitivity was also observed (Fig. 3): both $\mathrm{HOMA}_{\mathrm{ISI}}$ $(0.54 \pm 0.23$ compared with $0.24 \pm 0.11 ; P=0.0001)$

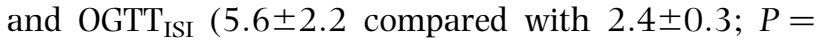
$0.0001)$ were significantly increased, without significant changes in BMI $\left(26.4 \pm 2.1 \mathrm{~kg} / \mathrm{m}^{2}\right.$ compared with $\left.27.1 \pm 1.8 \mathrm{~kg} / \mathrm{m}^{2} ; P=\mathrm{ns}\right)$. Although mean postoperative values of both indexes became greater than those in control individuals with high BMI, but remained lower than those in control individuals with normal BMI, the difference between cured patients with acromegaly and either control group was no longer significant.

\section{Relationships between cardiac mass, cardiac function and cardiovascular risk factors}

Before surgery No significant correlation could be found between indexes of insulin sensitivity and clinical BP or ABPM values, GH/IGF-I concentrations or BMI. A slight but significant correlation was found between both clinical and 24-h DBP and LVMI $(P<0.05)$ and between insulin sensitivity indexes and LVMI $(P=0.04$ for each parameter).

After surgery No significant correlation was observed between postoperative variations $(\Delta)$ in insulin sensitivity indexes $\left(\Delta \mathrm{HOMA}_{\mathrm{ISI}}\right.$ and $\left.\Delta \mathrm{OGTT}_{\mathrm{ISI}}\right)$ and $\Delta \mathrm{GH}$,
$\Delta$ IGF-I or $\Delta 24-\mathrm{h}$ SBP/DBP values (data not shown). As shown in Fig. 4, a marked inverse correlation was found between postoperative $\triangle \mathrm{LVMI}$ and both $\Delta \mathrm{HOMA}_{\mathrm{ISI}}$ and $\Delta \mathrm{OGTT}_{\mathrm{ISI}}(R=0.41, P=0.0005$ and $R=0.38, P=0.001$ respectively), contrasting with the lack of significant relationship between $\Delta$ LVMI and $\Delta \mathrm{GH}(R=0.18, P=0.19), \Delta \mathrm{IGF}-\mathrm{I}(R=0.09, P=$ 0.34 ) and $\Delta B P$ values (data not shown). Of note, the inverse relationship between $\triangle \mathrm{LVMI}$ and $\Delta \mathrm{HOMA}_{\mathrm{ISI}} /$ $\Delta$ OGTT $_{\text {ISI }}$ remained significant when $\Delta 24$-h SBP, $\Delta 24$-h DBP, $\Delta \mathrm{GH}$ or $\Delta$ IGF-I was introduced as single covariate in a multistep regression analysis $(P<0.01$ in all cases). $\Delta \mathrm{IRT}$ and $\Delta \mathrm{E} / \mathrm{A}$ ratio were found to correlate negatively with postoperative $\Delta$ LVMI $(P=0.023$, $R=0.24$ and $P=0.01, R=0.30$ respectively), but not with any other parameter mentioned.

\section{Discussion}

Although cardiovascular diseases classically represent the first cause of mortality in patients with acromegaly, evidence has been accumulating during the past decade that mortality may be reduced in those patients in whom the acromegaly is controlled $(5,36)$ and that normalization of GH/IGF-I hypersecretion is able to improve cardiac mass and function (19-23). A complex network of cardiovascular risk factors is present in patients with active acromegaly and it is likely that GH/IGF-I hypersecretion, in addition to its direct effects on the heart, can trigger a number of additional risk factors such as BP values and circadian rhythm, glucose tolerance and, in particular, insulin resistance, which has been directly implicated in 


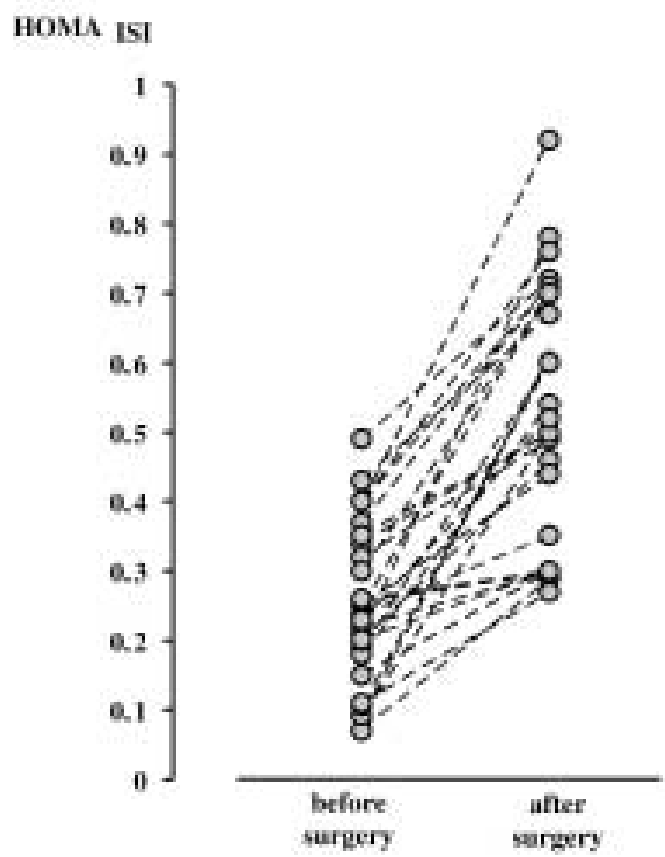

\section{OGTT ISI}

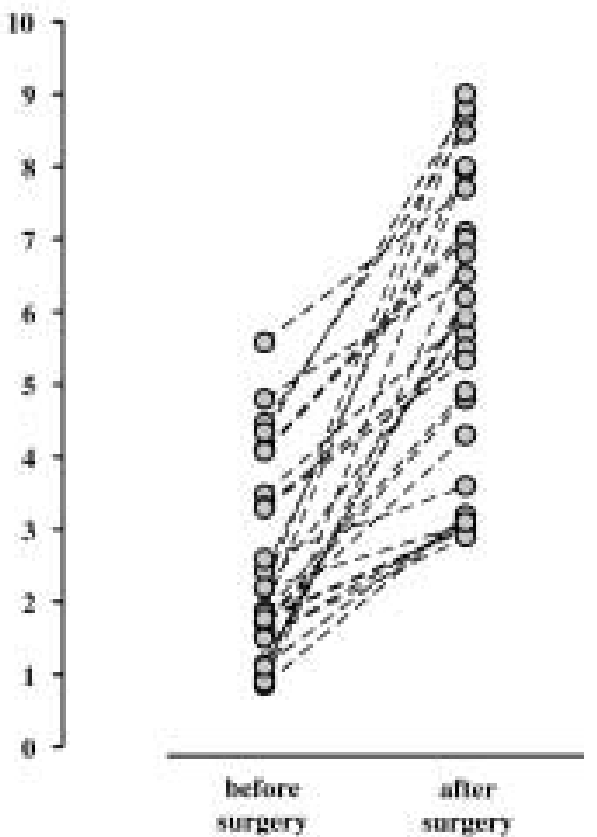

Figure 3 Effects of successful TSS on insulin sensitivity in patients with acromegaly. Pre- and postoperative individual values for

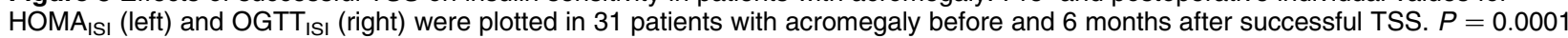
for each parameter.

essential hypertension and in a constellation of disorders, including obesity and abnormalities of glucose and lipid metabolism (37).

In the present study, we first confirmed that successful TSS significantly improved cardiac abnormalities in patients with acromegaly $(21-23)$, provided that strict criteria are retained to define surgical success $(22$, 23). We decided to focus on LVM and diastolic function, because systolic function is normal at rest until a late stage of the disease (6) and ejection fraction was normal in all our study patients before surgery (data not shown). It should be noted, however, that significant improvement in systolic function at peak exercise can also be observed after normalization of GH/IGF-I (38).

Our data confirm the significant cardiac improvement in successfully operated patients with acromegaly, but one finding of this study that is of primary importance is that postoperative normalization of GH/IGF-I secretion in these patients is also able to significantly reduce a number of associated cardiovascular risk factors, thereby confirming their relationship to hormone hypersecretion and suggesting that effective treatment of acromegaly may reduce the overall cardiovascular morbidity in these patients. In fact, a significant decrease in SBP was observed by clinical measurement and confirmed by ABPM, extending our previous findings in a smaller series of cured patients $(22,23)$, so that, according to current criteria (33), hypertension could be resolved in about 33\% of patients defined as hypertensive by ABPM before surgery. In addition, in agreement with the findings of previous studies $(14-16)$, a blunted circadian BP rhythm was present in about $50 \%$ of the patients with active acromegaly, but was restored in $80 \%$ after surgery. Of note, in a previous study, BP was not significantly influenced by surgery in patients who did not meet strict control for GH/IGF-hypersecretion (22, 23). In contrast, IGT and diabetes mellitus, which were present in about 33\% of the patients with active disease, were found to normalize in all cases of successful surgery. Although it extends our previous findings in a smaller series of elderly patients with acromegaly (23), this point is in apparent contrast with data in a recent report of a short-term postoperative study 7-14 days after surgery - in which glucose tolerance was normalized only in a subset of successfully operated patients (30). Normalization of glucose tolerance in the present study was accompanied by an impressive improvement in insulin sensitivity, as shown by signifi-

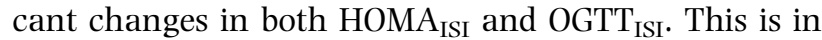
agreement with the findings of studies based on the euglycaemic clamp $(26,27)$ and with recent data on short-term postoperative HOMA ISI (30). Taken together, these results suggest that insulin sensitivity can improve quite quickly after surgery, whereas normalization of glucose tolerance in patients with acromegaly requires a sustained improvement of GH/IGF-I hypersecretion and insulin sensitivity.

Another endpoint of this study was to evaluate the possible role of postoperative variations in BP, glucose 
(a)

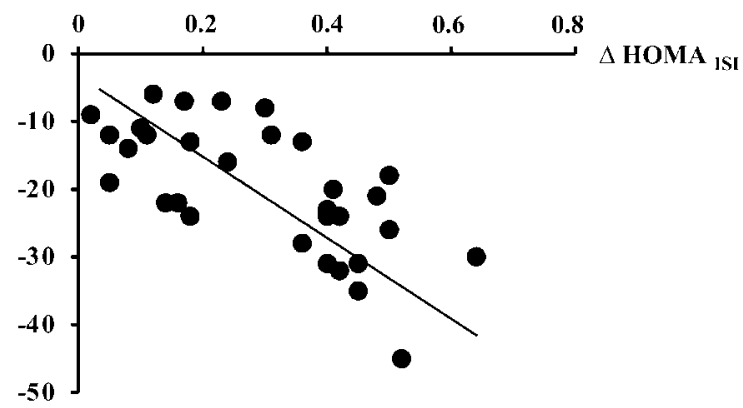

$\triangle \operatorname{LVMI}\left(\mathrm{g} / \mathrm{m}^{2}\right)$

(b)

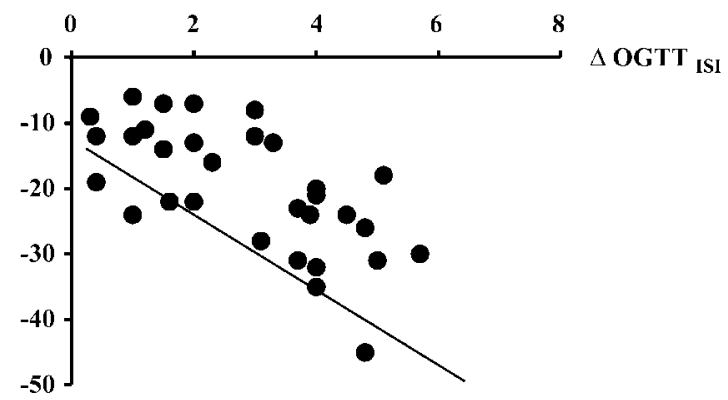

$\Delta \operatorname{LVMl}\left(\mathrm{g} / \mathrm{m}^{2}\right)$

Figure 4 Correlation between improvement in insulin sensitivity and reduction in cardiac mass in patients with acromegaly. The significant inverse relationship observed between $\Delta \mathrm{LVMI}$ and either $\Delta$ HOMA $_{\text {ISI }}(a)(R=0.41, P=0.0005)$ and $\Delta$ OGTT ISI $(b)$ ( $R=0.38, P=0.001$ ) is shown for 31 successfully operated patients with acromegaly.

tolerance and insulin sensitivity in the postoperative cardiac improvement observed in these patients. Signals for myocardial growth include metabolic factors such as GH/IGF-I hypersecretion $(10,11)$ and insulin resistance (39), and haemodynamic factors such as pressure and volume overload (40). The clinical importance of these factors has been documented largely in patients with essential hypertension, obesity, abnormalities of glucose tolerance and diabetes mellitus, in whom LVH and diastolic dysfunction have been linked to insulin resistance (41-43). Compensatory hyperinsulinaemia has been proposed as a possible mechanism leading to myocardial hypertrophy, in part by acting through the IGF-I receptors. A significant correlation was found between postoperative variations in insulin sensitivity and LVMI, which was further supported by a similar correlation between preoperative values for each parameter, and remained significant when 24-h BP values were introduced as covariates in a multifactorial analysis. In contrast, no significant correlation could be found between the postoperative variations in insulin sensitivity and 24-h SBP/DBP values or between the same parameters before surgery. Taken together, these data argue for a significant relationship between insulin resistance and LVH in acromegaly, independent of BP. Hypertension is likely to act as an additional risk factor, as supported herein by the slight but significant correlation between 24-h DBP and LVMI observed before surgery, and by the greater LVMI reported by others in hypertensive patients with acromegaly compared with their normotensive counterparts (14).

Although its molecular mechanisms have not been fully elucidated, insulin resistance has been widely documented in patients with acromegaly and consists of a reduced action of insulin on endogenous hepatic glucose production and peripheral glucose uptake (44-47). In the present study, preoperative insulin sensitivity was impaired compared with that in controls regardless of BMI, and no significant difference in insulin sensitivity could be found between patients with NGT and IGT, supporting the view that insulin resistance is a common event in patients with acromegaly and that only those who fail to counterbalance the reduced insulin sensitivity with increased $\beta$-cell function develop IGT and diabetes mellitus (30). Interestingly, the marked postoperative improvement in insulin sensitivity observed in cured patients occurred without significant changes in BMI. This should not be surprising because, as a result of significant changes in body composition (48), BMI is a poorly reliable index of fat mass in patients with acromegaly; this further indicates that GH/IGF-I hypersecretion contributes directly to insulin resistance in these patients. However, no significant relationship could be found between $\mathrm{HOMA}_{\mathrm{ISI}} / \mathrm{OGTT}_{\mathrm{ISI}}$ and GH/IGF-I concentrations before surgery, or between postoperative variations in the same parameters. Thus other factors such as the patient's age, disease duration, effective fat mass or genetic factors are likely to interact with GH/IGF-I hypersecretion to determine the degree of insulin resistance in an individual patient.

It is worthy of note that, although a significant postoperative improvement in diastolic dysfunction was also observed, no correlation was found between variations in IRT or E/A ratio and any hormonal or metabolic parameters or BP values. Left ventricular filling and relaxation improved with decreasing LVM, suggesting that improved diastolic function is a direct and non-specific consequence of reduction in cardiac mass. Indeed, ventricular hypertrophy helps preserving systolic function but may be deleterious for diastolic function, and alterations in diastolic relaxation have been reported to correlate well with the degree of ventricular hypertrophy $(49,50)$. Alternatively, the pathological features in the acromegalic heart that have been described previously (51), and which are believed to play a part in the precocious impairment of the viscoelastic properties of the myocardium, may be at least partly reversible with normalization of GH/IGF-I hypersecretion or insulin sensitivity.

In conclusion, this study in surgically cured patients provides indirect but significant insights into 
the pathogenesis of cardiovascular complications in acromegaly, giving indirect evidence that, in addition to GH/IGF-I hypersecretion per se and alterations in $\mathrm{BP}$, insulin resistance contributes to LVH in acromegaly. The postoperative improvement in insulin sensitivity, glucose tolerance and BP profile that accompany normalization of GH/IGF-I should further contribute to reducing the overall cardiovascular risk in these patients.

\section{References}

1 Nabarro JDN. Acromegaly. Clinical Endocrinology 198726 $481-512$.

2 Bengtsson BA, Eden S, Ernest I, Oden A \& Sjögren B. Epidemiology and long-term survival in acromegaly. Acta Medica Scandinavica $1988223327-335$.

3 Melmed S. Acromegaly. New England Journal of Medicine 1990 322 966-977.

4 Ezzat S, Forster MJ, Berchtold P, Redelmeier DA, Boerlin V \& Harris AG. Acromegaly. Clinical and biochemical features in 500 patients. Medicine 199473 233-240.

5 Rajasoorya C, Holdaway IM, Wrightson P, Scott DJ \& Ibbertson HK. Determinants of clinical outcome and survival in acromegaly. Clinical Endocrinology $1994 \mathbf{4 1}$ 95-102.

6 Saccà L, Cittadini A \& Fazio S. Growth hormone and the heart. Endocrine Reviews 199415 555-572.

7 Bertoni PD \& Morandi G. Impaired left ventricular diastolic function in acromegaly: an echocardiographic study. Acta Cardiolologica $1987421-10$.

8 Fazio S, Cittadini D, Sabatini D, Merola B, Colao AM, Biondi B et al. Evidence for biventricular involvement in acromegaly: a Doppler echocardiographic study. European Heart Journal 199314 26-33.

9 Minniti G, Jaffrain-Rea ML, Moroni C, Baldelli R, Ferretti E, Cassone $\mathrm{R}$ et al. Echocardiographic evidence for a direct of GH/IGF-I hypersecretion on cardiac mass and function in young acromegalics. Clinical Endocrinology 199849 101-106.

10 Timsit J, Riou B, Bertherat J, Wisnewski C, Kato NS, Weisberg AS et al. Effects of chronic GH hypersecretion on intrinsic contractility, energetics, isomyosin pattern and myosin adenosine triphosphatase activity of rat left ventricle. Journal of Clinical Investigation $199086507-513$.

11 Ito H, Hiroe M, Hirata Y, Motoyoshi T, Adachi S, Masayoshi S et al. Insulin-like growth factor-I induces hypertrophy with enhanced expression of muscle specific gene in rat cardiomyocytes. Circulation 199387 1715-1721.

12 Lopez-Velasco R, Escobar-Morreale HF, Vega B, Villa E, Sancho JM, Moya-Mur JL et al. Cardiac involvement in acromegaly: specific myocardiopathy or consequence of systemic hypertension? Journal of Clinical Endocrinology and Metabolism 199782 1047-1053.

13 Pickering TG. The clinical significance of of diurnal blood pressure variations. Dippers and non-dippers. Circulation $1990 \quad \mathbf{8 1}$ 700-702.

14 Terzolo M, Matrella C, Boccuzi A, Luceri S, Borriero M, Reimondo A et al. Twenty-four hour profile of blood presuure in patients with acromegaly: correlation with demographic, clinical and hormonal features. Journal of Endocrinological Investigation 199922 $48-54$.

15 Jaffrain-Rea ML, Moroni C, Baldelli R, Battista C, Maffei P, Terzolo $\mathrm{M}$ et al. Relationship between blood pressure and glucose tolerance in acromegaly. Clinical Endocrinology $2001 \quad \mathbf{5 4}$ 189-195.

16 Pietrobelli DJ, Akopian M, Olivieri AO, Renauld A, Garrido D, Artese R et al. Altered circadian blood pressure profile in patients with active acromegaly. Relationship with ventricular mass and hormonal values. Journal of Human Hypertension $2001 \mathbf{1 5}$ $601-605$.
17 Melmed S, Klibanski A, Reichlin S \& Thorner M. Recent advances in pathogenesis, diagnosis and management of acromegaly. Journal of Clinical Endocrinology and Metabolism $1995 \mathbf{8 0}$ 3395-3402.

18 Colao A, Baldelli R, Marzullo P, Ferretti E, Ferone D, Gargiulo P et al. Systemic hypertension and impaired glucose tolerance are independently correlated to the severity of the acromegalic cardiomyopathy. Journal of Clinical Endocrinology and Metabolism 2000 85 193-199.

19 Merola B, Cittadini A, Colao A, Ferone D, Fazio S, Sabatini D et al. Chronic treatment with the somatostatin analog octreotide improves cardiac abnormalities in acromegaly. Journal of Clinical Endocrinology and Metabolism 199377 790-793.

20 Baldelli R, Ferretti E, Jaffrain-Rea ML, Iacobellis G, Minniti G, Caracciolo B et al. Cardiac effects of slow-release lanreotide, a slowrelease somatostatin analog in acromegalic patients. Journal of Clinical Endocrinology and Metabolism 199984 527-532.

21 Hradec J, Marek J, Kral J, Janota T, Poloniecki J \& Malik M. Longterm echocardiographic follow-up acromegalic heart disease. American Journal of Cardiology 199372 205-210.

22 Minniti G, Moroni C, Jaffrain-Rea ML, Esposito V, Santoro A, Affricano C et al. Marked improvement of cardiovascular function after successful transsphenoidal surgery in acromegalic patients. Clinical Endocrinology 200155 307-313.

23 Minniti G, Jaffrain-Rea ML, Esposito V, Santoro A, Moroni C, Lenzi $\mathrm{J}$ et al. Surgical treatment and clinical outcome of GH-secreting adenomas in elderly patients. Acta Neurochirurgica (Wien) 2001 $1431205-1211$.

24 Mancia G, Di Rienzo M \& Parati G. Ambulatory blood pressure monitoring use in hypertension research and clinical practice. Hypertension 199321 510-525.

25 Mallion JM, Baguet JP, Siche JP, Tremel F \& De Gaudemaris R. Clinical value of ambulatory blood pressure monitoring. Journal of Hypertension 199917 585-595.

26 Moller N, Schmitz O, Jorgensen JO, Astrup J, Bak JF, Christensen SE et al. Basal- and insulin-stimulated substrate metabolism in patients with active acromegaly before and after adenomectomy. Journal of Clinical Endocrinology and Metabolism $1992 \mathbf{7 4}$ 1012-1019.

27 Wasada T, Aoki K, Katsumori K, Muto K, Tomonaga O, Yokoyama $\mathrm{H}$ et al. Assessment of insulin resistance in acromegaly associated with diabetes mellitus before and after transsphenoidal adenomectomy. Endocrine Journal 1997 44 617-620.

28 Matthews DR, Hosker JP, Rudenski AS, Naylor BA, Treacher DF \& Turner RC. Homeostasis model assessment: insulin resistance and $\beta$-cell function from fasting plasma glucose and insulin concentrations in man. Diabetologia $1985 \mathbf{2 8} 412-419$.

29 Matsuda M \& DeFronzo RA. Insulin sensitivity indices obtained from oral glucose tolerance testing. Diabetes Care 199922 $1462-1470$.

30 Kasayama S, Otsuki M, Takagi M, Saito H, Sumitani S, Kouhara H et al. Impaired $\beta$-cell function in the presence of reduced insulin sensitivity determines glucose tolerance status in acromegalic patients. Clinical Endocrinology 200052 549-555.

31 Giustina A, Barkan A, Casanueva FF, Cavagnini F, Frohman L, Ho K et al. Criteria for cure of acromegaly: a consensus conference. Journal of Clinical Endocrinology and Metabolism $2000 \mathbf{8 5}$ 526-529.

32 Devereux RB. Detection of left ventricular hypertrophy by M-mode echocardiography. Anatomic validation, standardization and comparison to the other methods. Hypertension 19879 $19-26$.

33 Joint National Committee (JNC) on prevention, detection, evaluation and treatment of high blood pressure, The Sixth Report. Archives of Internal Medicine 1997157 2414-2446.

34 Van Hoof R, Hespel P, Fargard R, Lijnen P, Staessen J \& Amery A. Effect of endurance training on blood pressure at rest, during exercise and during 24 hours in sedentary men. American Journal of Cardiology 198963 845-849. 
35 The Expert Committee on the Diagnosis and Classification of Diabetes Mellitus, Report of the Expert Committee on the Diagnosis and Classification of Diabetes Mellitus. Diabetes Care 199821 (Suppl 1) S5-S19.

36 Bates AS, Van't Hoff W, Jones JM \& Clayton RN. An audit of outcome of treatment in acromegaly. Quarterly Journal of Medicine $199386293-299$.

37 De Fronzo R \& Ferrannini E. Insulin resistance: a multifaceted syndrome responsible for NIDDM, obesity, hypertension, dyslipidemia and ASCVD. Diabetes Care Review 199114 173-194.

38 Colao A, Cuocolo A, Marzullo P, Nicolai E, Ferone D \& Della Morte AM. Is the acromegalic cardiomyopathy reversible? Effect of 5-year normalization of growth hormone and insulinlike growth factor I levels on cardiac performance. Journal of Clinical Endocrinology and Metabolism 200186 1551-1557.

39 Philips RA, Krakoff LR, Dunaif A, Finegood DT, Gorlin R \& Shimabukuro S. Relation among left ventricular mass, insulin resistance and blood pressure in nonobese subjects. Journal of Clinical Endocrinology and Metabolism $1998 \mathbf{8 3} 4284-4288$.

40 Ganau A, Devereux RB, Pickering TG, Roman MJ, Schnall PL, Santucci S et al. Relation of left ventricular hemodynamic load and contractile performance to left ventricular mass in hypertension. Circulation $19908125-36$.

41 Sasson Z, Rasooly Y, Bhesania T \& Rasooly I. Insulin resistance is an important determinant of left ventricular mass in the obese. Circulation 199388 1431-1436.

42 Lind L, Andersson PE, Andren B, Hanni A \& Lithell HO. Left ventricular hypertrophy in hypertension is associated with the insulin resistance metabolic syndrome. Journal of Hypertension $199513433-438$.

43 Watanabe K, Sekiya M, Tsuruoka T, Funada J \& Kameoka H. Effect of insulin resistance on left ventricular hypertrophy and dysfunction in essential hypertension. Journal of Hypertension $1999171153-1160$.
44 Hansen I, Tsalikian E, Beaufrère B, Gerich G, Haymond M \& Rizza R. Insulin resistance in acromegaly: defects in both hepatic and extrahepatic insulin action. American Journal of Physiology 250 E269-E273.

45 Moller N, Butler PC, Antsiferov MA \& Alberti KG. Effects of growth hormone on insulin sensitivity and forearm metabolism in normal men. Diabetologia 198932 105-110.

46 Foss MC, Saad MJ, Paccola GM, Paula FJ, Piccinato CE \& Moreira AC. Peripheral glucose metabolism in acromegaly. Journal of Clinical Endocrinology and Metabolism 199172 1048-1053.

47 O'Sullivan AJ, Kelly JJ, Hoffman DM, Baxter RC \& Ho KK. Energy metabolism and substrate oxidation in acromegaly. Journal of Clinical Endocrinology and Metabolism 199580 486-491.

48 O'Sullivan AJ, Kelly JJ, Hoffman DM, Freund J \& Ho KK. Body composition and energy expenditure in acromegaly. Journal of Clinical Endocrinology and Metabolism 199478 381-386.

49 Shapiro LM \& McKenna WJ. Left ventricular hypertrophy. Relation of structure to diastolic function in hypertension. British Heart Journal $1983 \mathbf{5 1} 637-642$.

50 Wachtell K, Smith G, Gerdts E, Dahlof B, Nieminen MS, Papademetriou $V$ et al. Left ventricular filling patterns in patients with systemic hypertension and left ventricular hypertrophy (the LIFE study). Losartan intervention for endpoint. American Journal of Cardiology 200085 466-472.

51 Lie JT \& Grossman SJ. Pathology of the heart in acromegaly: anatomic findings in 27 autopsied patients. American Heart Journal $1980 \mathbf{1 0 0} 41-52$.

Received 5 July 2002

Accepted 4 November 2002 